\title{
Caspase-Dependent and -Independent Cell Death Induced by 3-Nitropropionic Acid in Rat Cortical Neurons
}

\author{
Sandra Almeida, Ana C. Brett, Inês N. Góis, Catarina R. Oliveira, and A. Cristina Rego* \\ Institute of Biochemistry, Faculty of Medicine, University of Coimbra and Center for Neuroscience \\ and Cell Biology of Coimbra, Coimbra, Portugal
}

\begin{abstract}
Mitochondria play a critical role in cell death by releasing apoptogenic factors, such as cytochrome c and apoptosis-inducing factor (AIF), from the intermembrane space into the cytoplasm. Because mitochondrial dysfunction has been shown to be involved in several neurodegenerative diseases, mitochondrial toxins are largely used to model these disorders. These include 3-nitropropionic acid (3-NP), an irreversible inhibitor of succinate dehydrogenase, which has been used to model Huntington's disease and was previously reported by us to induce apoptotic cell death through caspase activation. In the present study, we evaluated the involvement of caspase-independent neuronal cell death induced by 3-NP (1 mM) and the effect of z-VDVAD-fmk, an inhibitor of caspase-2, using cortical neurons in culture. Our results highly suggest that 3-NP induces both caspase-dependent and -independent cell death. We showed that $z-$ VDVAD-fmk prevented both caspase-2 and -3-like activities evoked by 3-NP, but only partly prevented chromatin fragmentation/condensation. However, z-VDVAD-fmk did not avoid 3-NP-induced release of cytochrome c or AIF from mitochondria nor did it affect the levels of mitochondrial Bax. Furthermore, 3-NP-mediated decrease in plasma membrane integrity was not affected by z-VDVAD-fmk. Under these conditions, the inhibitor prevented the caspasedependent cell death. J. Cell. Biochem. 98: 93-101, 2006. ㄷ 2005 Wiley-Liss, Inc.
\end{abstract}

Key words: caspase; 3-nitropropionic acid; mitochondria; AIF, cortical neurons; Huntington's disease

Caspases are cysteine proteases that mediate apoptotic cell death in a variety of cells, including neurons. Caspases can be activated through extrinsic or intrinsic pathways. The latter is used by most neurons in several pathological conditions. This pathway implicates the release of cytochrome $\mathrm{c}$ from mitochondria, which recruits Apaf-1 and procaspase-9, forming the apoptosome. As a consequence, caspase-9 is activated and subse-

Grant sponsor: "Gabinete de Apoio à Investigação" (GAI, Faculty of Medicine, University of Coimbra); Grant number: GAI 21/03; Grant sponsor: "Fundação para a Ciência e a Tecnologia" (FCT), Portugal; Grant number: POCI/SAU-NEU/57310/2004.

*Correspondence to: A. Cristina Rego, PhD, Center for Neuroscience and Cell Biology of Coimbra and Institute of Biochemistry, Faculty of Medicine, University of Coimbra, 3004-504 Coimbra, Portugal. E-mail: acrego@cnc.cj.uc.pt

Received 11 October 2005; Accepted 28 October 2005

DOI 10.1002/jcb.20748

(c) 2005 Wiley-Liss, Inc. quently other caspases are also activated. Although caspase-9 is generally believed to be the initiator caspase in stress-induced apoptosis, more recent studies suggest that caspase-2 can act upstream of mitochondria [Lassus et al., 2002; Robertson et al., 2002]. According to this, caspase-2 can induce cytochrome c, Smac and apoptosis-inducing factor (AIF) release from mitochondria [Guo et al., 2002; Paroni et al., 2002; Robertson et al., 2002]. It was also described that procaspase- 2 can be recruited to a high molecular weight complex (similar to the apoptosome in which procaspase-9 is activated) independently from cytochrome $c$ and Apaf-1. The recruitment of caspase- 2 to this complex is sufficient to mediate its activation [Read et al., 2002]. The individual components of this complex have yet to be identified.

In addition to the pathway described above, in which cell death is mediated by caspase activation, there are other pathways leading to cell death that do not rely on the activity of caspases. In this form of cell death, two endonucleases, AIF and endonuclease G, are 
Almeida et al.

proposed to translocate from the mitochondrial intermembrane space to the nucleus, where they are involved in DNA fragmentation and chromatin condensation [Susin et al., 1999; Li et al., 2001]. Whether these proteins are coreleased during apoptosis or require activation of initiator caspases remains controversial.

There is substantial evidence that apoptosis and caspase activation contribute to neurodegeneration associated with Huntington's disease (HD) [Portera-Cailliau et al., 1995; Kiechle et al., 2002]. Caspase-1, -3, -8 and -9 activation has been demonstrated in end-stage HD transgenic mice or in post-mortem human HD brain [Ona et al., 1999; Sanchez et al., 1999; Chen et al., 2000; Kiechle et al., 2002]. More recent studies reported that caspase- 2 and -6 also play important roles in HD pathogenesis [Hermel et al., 2004]. Using a mitochondrial model of $\mathrm{HD}$, the 3-nitropropionic acid (3-NP), we previously showed that Bcl-2 overexpression prevented the activation of caspase- $2,-3$ and -6 induced by 3 -NP $(0.3 \mathrm{mM})$ [Brito et al., 2003]. We also demonstrated that cytochrome cdependent activation of caspase- 3 could be prevented by regulating Bcl-2 family proteins in the mitochondria, in the presence FK506, a classical inhibitor of calcineurin [Almeida et al., 2004]. Because we observed that caspase- 2 was also activated by 3 -NP concentrations $\geq 1 \mathrm{mM}$, in the present study we examine the effect of $\mathrm{z}$ VDVAD-fmk, a caspase-2 inhibitor, on 3-NPinduced cell death using rat primary cortical neurons. Our results show that cell death evoked by 3 -NP is only partly mediated by caspase activation. The observation that AIF is released from mitochondria suggests a caspaseindependent cell death pathway. The inhibition of caspase- 2 and -3 by z-VDVAD-fmk counteracted the activation of the caspase-dependent pathway, partly preventing cell death involving chromatin fragmentation/condensation.

\section{MATERIALS AND METHODS}

\section{Materials}

Neurobasal medium and B-27 supplement were purchased from GIBCO (Paisley, UK). 3Nitropropionic acid, 3-(4,5-dimethylthiazol-2yl)-2,5-diphenyltetrazolium bromide (MTT), benzyloxycarbonyl-Val-Asp-Val-Ala-Asp-fluoromethyl ketone (z-VDVAD-fmk), N-acetyl-ValAsp-Val-Ala-Asp-p-nitroanilide (Ac-VDVADpNA) and anti- $\alpha$-tubulin were from Sigma
Chemical Co. (St. Louis, MO). N-acetyl-AspGlu-Val-Asp-p-nitroanilide (Ac-DEVD-pNA) was obtained from Calbiochem (Darmstadt, Germany). Primary antibodies anti-cytochrome c, anti-Bax and anti-AIF were from PharMingen (San Diego, CA), Cell Signaling (Beverly, MA) and Santa Cruz Biotechnology, Inc. (Santa Cruz, CA), respectively. Hoechst 33342 and Mitotracker-red CMXRos were from Molecular Probes (Eugene, OR). All other reagents were of analytical grade.

\section{Cell Culture}

Primary neuronal cultures of rat cerebral cortical neurons were prepared as previously described [Almeida et al., 2004]. In brief, cerebral cortices were dissected from fetal rats of the Wistar strain at 16-17 days and the cells dissociated. After that, cells were resuspended in Neurobasal medium supplemented with $2 \%$ B-27, $0.2 \mathrm{mM}$ glutamine, $100 \mathrm{U} / \mathrm{ml}$ penicillin and $0.1 \mathrm{mg} / \mathrm{ml}$ streptomycin and cultured in a humidified incubator at $37^{\circ} \mathrm{C}(95 \%$ air and $5 \%$ $\mathrm{CO}_{2}$ ). After 5-6 days in culture, neurons were incubated with $1 \mathrm{mM} 3$-NP for $24 \mathrm{~h}$. When applied, the cells were pretreated for 20-30 min with 1 or $3 \mu \mathrm{M}$ z-VDVAD-fmk, a cell permeable inhibitor that contains the aminoacid sequence recognised by caspase-2 [Talanian et al., 1997], before incubation with 3-NP. The stock solution of 3-NP was prepared in water and brought to $\mathrm{pH} 7.4$ with $\mathrm{NaOH}$. Stock solutions of $\mathrm{z}$ VDVAD-fmk were prepared in DMSO.

\section{MTT Assay}

The reduction status of cells was measured by a colorimetric assay for cell survival, using 3(4,5-dimethylthiazol-2-yl)-2,5-diphenyltetrazolium bromide (MTT), according to the method described by Mosmann [1983]. MTT $(0.5 \mathrm{mg} / \mathrm{ml})$ in $\mathrm{Na}^{+}$medium (in $\mathrm{mM}$ : $132 \mathrm{NaCl}, 1.2$ $\mathrm{NaH}_{2} \mathrm{PO}_{4}, 1.4 \mathrm{MgCl}_{2}, 4 \mathrm{KCl}, 10$ HEPES, 6 glucose and $1 \mathrm{CaCl}_{2}, \mathrm{pH}$ 7.4) was added to the cultures and incubated for $2 \mathrm{~h}$ at $37^{\circ} \mathrm{C}$ in the dark. When taken up by living cells, MTT is converted to a water-insoluble blue product (formazan). The precipitated dye was dissolved in $0.04 \mathrm{M} \mathrm{HCl}$ in isopropanol and colorimetrically quantitated (absorbance at $570 \mathrm{~nm}$ ). Values were expressed as the percentage of optical density of control cells, in the absence of 3 -NP or z-VDVAD-fmk. To exclude the possible effect of DMSO (used as a vehicle) per se, control 
cells were treated with DMSO $(\sim 0.1 \%$ in the medium).

\section{Lactate Dehydrogenase (LDH) Measurements}

Assessment of intracellular LDH was determined after lysing the cells with $10 \mathrm{mM}$ HEPES (pH 7.4) plus $0.01 \%$ Triton $\mathrm{X}-100$, and freezing at $-80^{\circ} \mathrm{C}$. Cell debris in both aliquots (intra and extracellular) were removed by centrifugation at 14,000 rpm (Eppendorf Centrifuge 5417R), for $10 \mathrm{~min}$. LDH activity was determined spectrophotometrically (Perkin-Elmer Lambda-2), by following the rate of conversion of reduced nicotinamide adenine dinucleotide $(\mathrm{NADH})$ to oxidised nicotinamide adenine dinucleotide $\left(\mathrm{NAD}^{+}\right)$at $340 \mathrm{~nm}$, according to the method of Bergmeyer and Bernt [1974]. LDH released into the extracellular medium was expressed as a percentage of total LDH activity in the cells.

\section{Caspase Protease Activity Assay}

Caspase-like activities were determined as described previously [Almeida et al., 2004]. Briefly, cortical cells were lysed and centrifuged at 14,000 rpm (Eppendorf Centrifuge 5417R) for $10 \mathrm{~min}$. The resulting supernatants were assayed for protein content by the Sedmak method [Sedmak and Grossero, 1977]. Caspase-2 and -3-like activities were tested on peptidic substrates using, respectively, AcVDVAD-pNA and Ac-DEVD-pNA. Caspase-like activities were calculated as the increase above the control, for equal protein loading $(25 \mu \mathrm{g})$.

\section{Nuclear Morphology Assay}

The nuclear morphology of cortical neurons was analysed by fluorescence microscopy using Hoechst 33342 dye. After incubation for $24 \mathrm{~h}$, the medium was replaced by new Neurobasal medium and the cortical neurons remained in culture for an additional $24 \mathrm{~h}$ (without $\mathrm{z}$ VDVAD-fmk or 3-NP). Then, cells were washed briefly in phosphate buffer (PBS, in mM: 137 $\mathrm{NaCl}, 2.7 \mathrm{KCl}, 1.4 \mathrm{~K}_{2} \mathrm{HPO}_{4}, 4.3 \mathrm{Na}_{2} \mathrm{HPO} 4$, $\mathrm{pH}$ 7.4), fixed in $4 \%$ paraformaldehyde $(\mathrm{pH}$ 7.4) for $10 \mathrm{~min}$ and incubated with $7.5 \mu \mathrm{g} / \mathrm{ml}$ Hoechst for $10 \mathrm{~min}$. After washing twice in PBS, the coverslips were immobilized on a glass slide with mounting medium. Fluorescence of stained chromatin was examined and the fragmented and condensed chromatin was scored using a Nikon Diaphot TMD microscope (Nikon Corporation, Tokyo, Japan), with a triple XF-63 Omega filter (Omega Optical, Inc., Brattleboro, VT).

\section{Immunocytochemistry}

After incubation for $24 \mathrm{~h}$, cells were exposed to $750 \mathrm{nM}$ Mitotracker-red in $\mathrm{Na}^{+}$medium for $1 \mathrm{~h}$, at $37^{\circ} \mathrm{C}$ in the dark. Then, cells were washed in PBS, fixed in 4\% paraformaldehyde ( $\mathrm{pH} 7.4$ ) for $10 \mathrm{~min}$ and incubated in PBS containing $20 \mathrm{mM}$ glycine for $10 \mathrm{~min}$. The cells were permeabilised with $0.1 \%$ saponin in PBS for $30 \mathrm{~min}$ and incubated with anti-cytochrome c (1:100, against its native form) for another $30 \mathrm{~min}$. Next, cells were washed and incubated with Alexa Fluor 488 (1:200) for $30 \mathrm{~min}$. After washing twice in PBS, the coverslips were immobilized on a glass slide with mounting medium and fluorescence was examined by confocal microscopy (Bio-Rad MRC 600).

\section{Western Blotting Analysis}

Mitochondrial fractions were prepared from cortical neurons as described previously [Almeida et al., 2004]. Protein content was determined using the Bio-Rad reagent according to the manufacturer's instructions. Equivalent amounts of protein were separated on a 15\% SDS-PAGE gel and electroblotted onto polyvinylidene difluoride (PVDF) membranes (Amersham). After blocking with 5\% skim milk in TBS (25 mM Tris/HCl, pH 7.6, $150 \mathrm{mM} \mathrm{NaCl}$ )/ $0.1 \%$ Tween, for $2 \mathrm{~h}(\mathrm{RT})$, the membranes were incubated with the antibodies directed against the denatured form of cytochrome c (1:500), Bax (1:1,000), or AIF (1:1,000) overnight, at $4{ }^{\circ} \mathrm{C}$. The membranes were further incubated with the secondary antibody (1:20,000) for $2 \mathrm{~h}$ (RT) and the proteins were visualized by using an enhanced chemifluorescence reagent (Amersham Biosciences, Buckinghamshire, UK). The antibody directed against $\alpha$-tubulin $(1: 20,000)$ was used to normalize the amount of protein per lane.

\section{Statistical Analysis}

Data were expressed as mean \pm SEM of the number of experiments indicated in the figure legends. Comparisons among multiple groups were performed with a one-way analysis of variance (ANOVA) followed by a Tukey-Kramer post-hoc test. Comparisons between two groups were achieved with Student's $t$-test (GraphPad Prism version 3.0). Significance was accepted at $P<0.05$. 


\section{RESULTS}

We have previously reported that exposure of rat cortical neurons to 3-NP induces activation of several caspases, namely caspase- $2,-3,-8$ and -9 , in a dose dependent manner [Almeida et al., 2004]. In the present study, we determined the effect of z-VDVAD-fmk, a cell-permeable inhibitor that contains the aminoacid sequence recognised by caspase-2 [Talanian et al., 1997], in primary cortical neurons exposed to $1 \mathrm{mM}$ 3-NP, a concentration shown to significantly increase the activity of caspase- 2 [Almeida et al., 2004]. As shown in Figure 1 (A, B), $1 \mathrm{mM}$ 3-NP induced a 2.5-fold increase in both caspase-2 and -3-like activities. A concentration of $3 \mu \mathrm{M} \mathrm{z}$-VDVAD-fmk was required to completely prevent caspase-2-like activity $(P<0.01)$. Under these conditions caspase-3like activity was also completely prevented $(P<0.01)$ (Fig. 1B).

Because z-VDVAD-fmk completely prevented both caspase- 2 and -3 activities, we next examined the effect of the inhibitor in the mitochondrial apoptotic pathway, by analysing the levels of pro-apoptotic proteins. Using Mitotracker-red, a mitochondrial marker also sensitive to mitochondrial membrane potential [Bae et al., 2005], we observed that z-VDVAD-fmk did not prevent the decrease in mitochondrial mem- brane potential induced by 3-NP (Fig. 2A). z-VDVAD-fmk was also unable to prevent the loss of mitochondrial cytochrome c (Fig. 2A,B) induced by $3-\mathrm{NP}$, as observed by immunocytochemistry and Western blotting. Labelling of cytochrome $\mathrm{c}$ in cytosolic fractions was not changes by z-VDVAD-fmk either (data not shown). In fact, the inhibitor decreased mitochondrial cytochrome c per se by about $20 \%$ (Fig. 2B), but did not affect the labelling of Mitotracker-red (Fig. 2A). We also observed that $\mathrm{z}$-VDVAD-fmk did not prevent the decrease of mitochondrial AIF induced by 3-NP (Fig. 2C). Furthermore, both mitochondrial (Fig. 2D) and cytosolic (data not shown) Bax levels remained unchanged upon exposure to 3-NP and/or z-VDVAD-fmk.

As a means to evaluate the role of the inhibitor in preventing cell death due to inhibition of caspase-3, we next analysed cells entering into apoptosis by examining the nuclear morphology of cortical neurons exposed to $1 \mathrm{mM}$ 3 -NP for $24 \mathrm{~h}$, plus $24 \mathrm{~h}$ in the absence of any stimuli, using Hoechst 33342 (Fig. 3). This dye allows the measurement of chromatin alterations due to caspase-3 activation and AIF release. Other methods like DNA laddering only measure caspases contribution, since caspase-independent cell death does not lead to a DNA laddering pattern [Maianski et al., 2003;
A

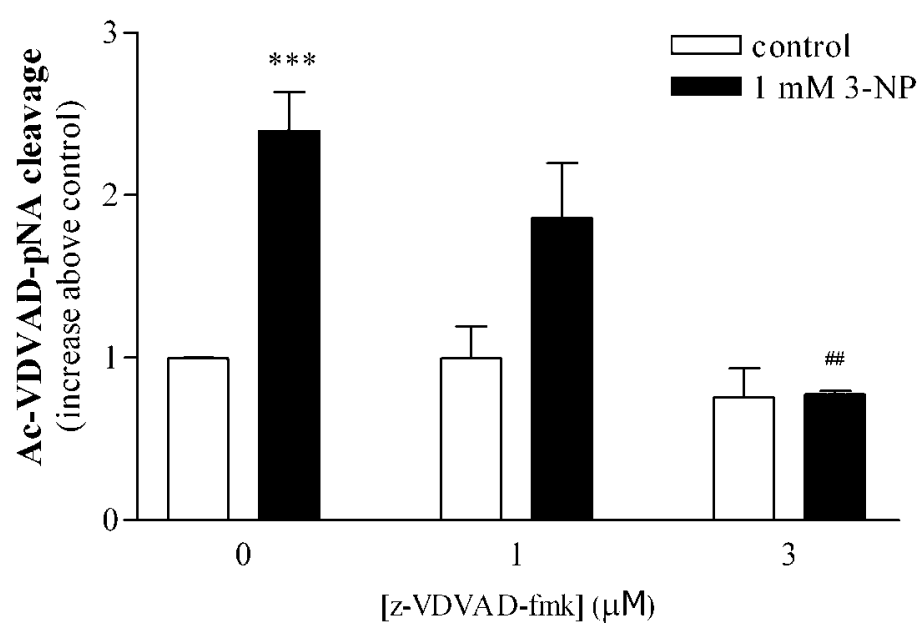

B Caspase-3

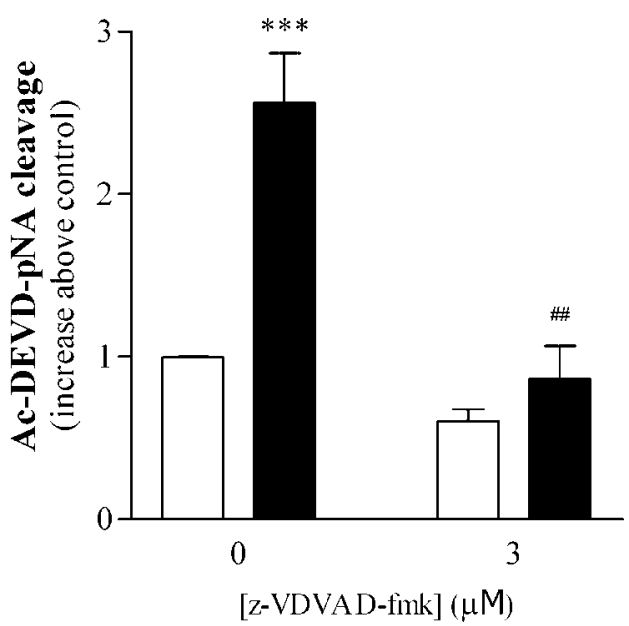

Fig. 1. 3-NP-mediated caspase-2 and -3 activation-effect of zVDVAD-fmk. Cortical cultures were pretreated with 1 or $3 \mu \mathrm{Mz}$ VDVAD-fmk and then incubated in the absence or in the presence of $1 \mathrm{mM}$ 3-NP, for $24 \mathrm{~h}$. Caspase-2 (A) or caspase-3 (B) -like activities were measured by following the cleavage of the colorimetric substrates Ac-VDVAD-pNA or Ac-DEVD-pNA, respectively. The activity was expressed as the increase of optical density above the control (cells maintained in the absence of 3-NP and z-VDVAD-fmk). The results were expressed as the mean \pm SEM of three to six distinct experiments. Statistical analysis: ${ }^{* * *} P<0.001$, compared to the control; ${ }^{\# \#} P<0.01$, compared to 3-NP-treated neurons, in the absence of Z-VDVADfmk. 

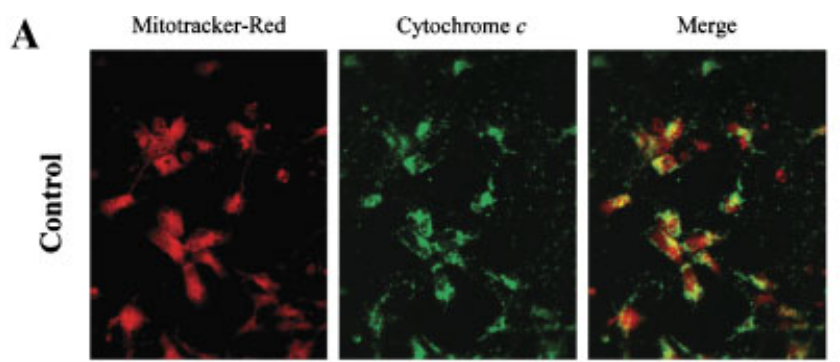

B
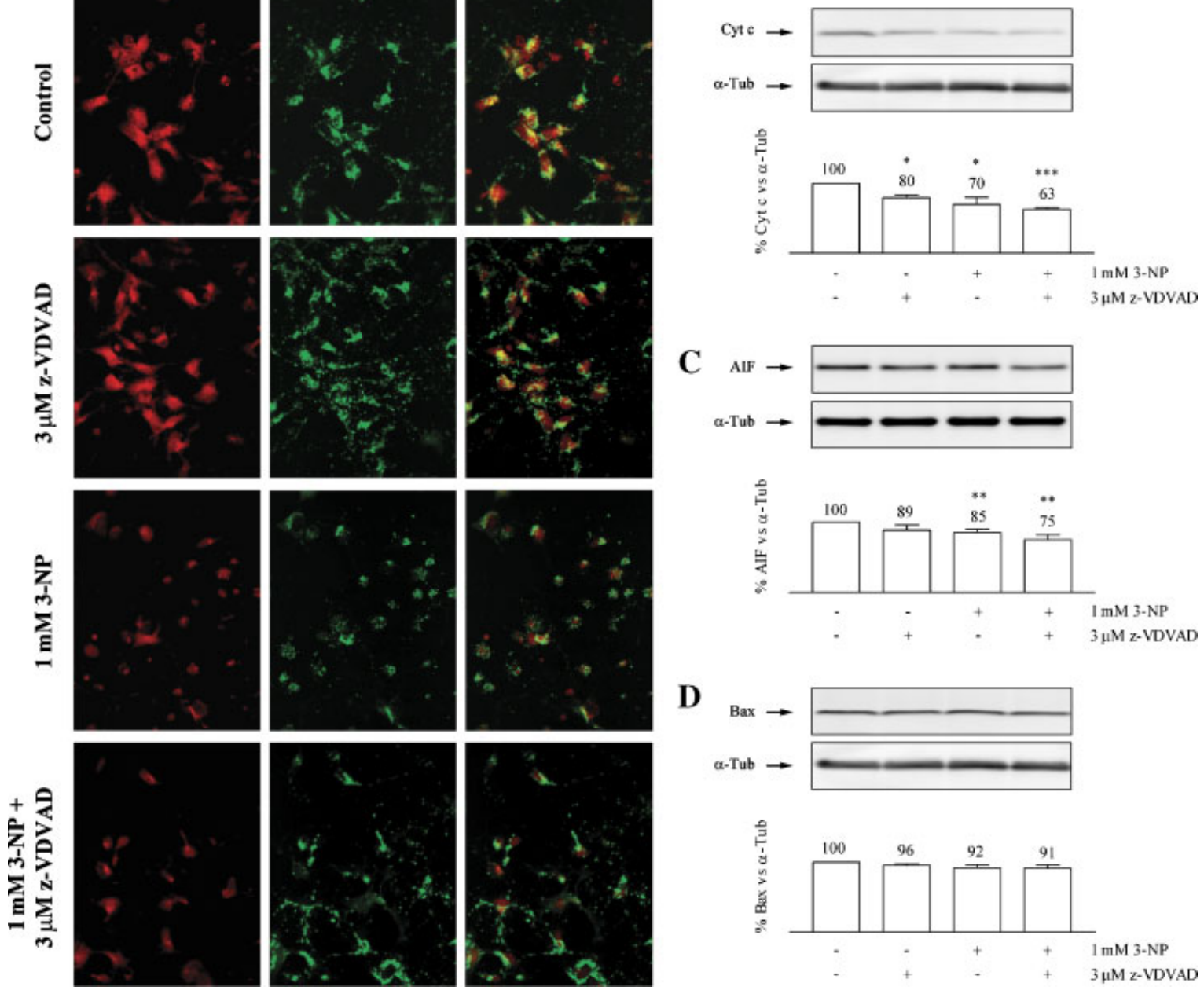

Fig. 2. Effect of 3-NP and z-VDVAD-fmk on mitochondrial proteins. Cortical neurons were pretreated with $3 \mu \mathrm{Mz}$-VDVAD$\mathrm{fmk}$ and then incubated in the absence or in the presence of $1 \mathrm{mM}$ 3-NP, for 24 h. A: Cells were labelled with Mitotracker-red (red) and cytochrome c (green). Fluorescence co-localisation (yellow) indicates retention of cytochrome $\mathrm{c}$ in the mitochondria. B, C, D: Mitochondrial fractions prepared from cortical neurons were analyzed by SDS-PAGE followed by Western blotting for

cytochrome c (B), AIF (C) and Bax (D). Blots are representative from three to four different experiments producing the same results. Graphs show densitometric analysis performed by normalizing the bands of mitochondrial proteins to $\alpha$-tubulin. Data were expressed as the mean \pm SEM of all experiments. Statistical analysis: ${ }^{*} P<0.05,{ }^{* *} P<0.01,{ }^{* * *} P<0.001$, compared to untreated neurons. [Color figure can be viewed in the online issue, which is available at www.interscience.wiley.com.]

Chipuk and Green, 2005]. Control cells showed about $24.8 \pm 1.1 \%$ apoptotic cells, with condensed and/or fragmented chromatin. In the presence of $1 \mathrm{mM} 3-\mathrm{NP}$, the number of viable cells decreased about $22.4 \pm 2.5 \%(P<0.01)$, relatively to the control (untreated neurons). Under these conditions, z-VDVAD-fmk only partly prevented 3-NP-induced apoptotic morphology (by $8.1 \pm 1.1 \%, P<0.05$ ) (Fig. 3A,B). In addition, we analysed the effect of the inhibitor on the reducing capacity of cortical neurons and on the integrity of plasma membrane, by following the MTT reduction assay and the leakage of $\mathrm{LDH}$, respectively. 3-NP (1 mM)

decreased the capacity of cells to reduce MTT by $29.1 \pm 0.8 \%(P<0.001)$ (Fig. $4 \mathrm{~A})$, and increased the $\mathrm{LDH}$ released into the medium by $8.3 \pm 2.4 \%(P<0.05)$ over the control (Fig. $4 \mathrm{~B})$. However, the caspase inhibitor did not prevent these alterations.

These results suggested that chromatin fragmentation/condensation induced by $1 \mathrm{mM} 3-\mathrm{NP}$ results from both cytochrome c-mediated caspase-3 activation and AIF released from mitochondria, in a process that does not depend on Bax translocation to this organelle. Under the concentration affecting caspase-2 activity, z-VDVAD-fmk ( $3 \mu \mathrm{M})$ did not prevent 
A
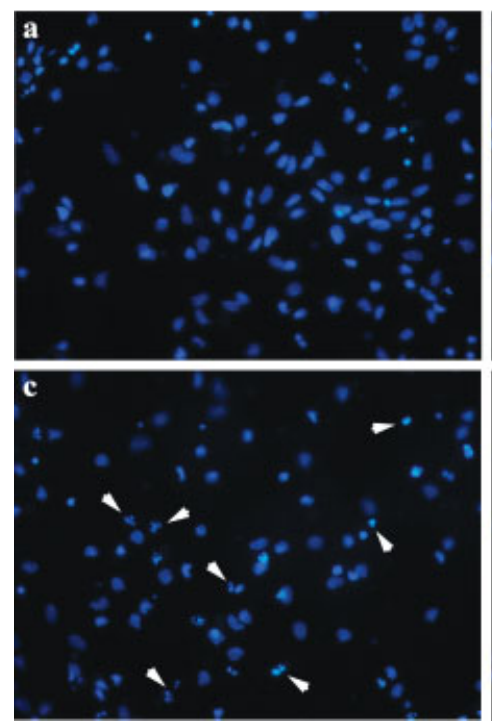

Fig. 3. Effect of $z-V D V A D-f m k$ on chromatin morphology upon exposure to 3-NP. The cells were pretreated with $3 \mu \mathrm{M} \mathrm{z}$ VDVAD-fmk and further exposed to $1 \mathrm{mM} 3-\mathrm{NP}$, for $24 \mathrm{~h}$. After incubation, the medium was replaced by new Neurobasal medium and the cortical neurons remained in culture for more $24 \mathrm{~h}$ (without z-VDVAD-fmk or 3-NP). Fixed cells were labelled with Hoechst 33342 and assayed for chromatin fragmentation/ condensation. A: Representative images of the cells: a, untreated cells; b, $3 \mu \mathrm{M}$ z-VDVAD-fmk; c, 1 mM 3-NP; d, z-VDVAD-fmk plus 3-NP. The arrows show fragmented/condensed chromatin.

mitochondria permeabilization, nor did it affect the loss of cell viability, suggesting that part of the protective effect observed in Figure 3, may result from the inhibition of caspase-3.

\section{DISCUSSION}

In the present study, we show that 3-NP $(1 \mathrm{mM})$ induces the release of mitochondrial cytochrome $c$ and AIF. $z$-VDVAD-fmk prevents both caspase- 2 and -3-like activities induced by 3 -NP and slightly prevents chromatin fragmentation/condensation. However, z-VDVAD-fmk does not prevent 3-NP-induced release of cytochrome c or AIF from mitochondria, nor does it affect necrotic/late apoptotic features of cell death, determined by loss of plasma membrane integrity.

During the past years large amount of information has been gathered to elucidate the mechanism leading to cell death upon 3-NP treatment. Using the same concentration of 3NP as in the present study, Pang and Geddes [1997] showed 50\% hippocampal cell loss after $48 \mathrm{~h}$ of treatment, which corresponded to both necrotic and apoptotic features. Although the

\section{B}

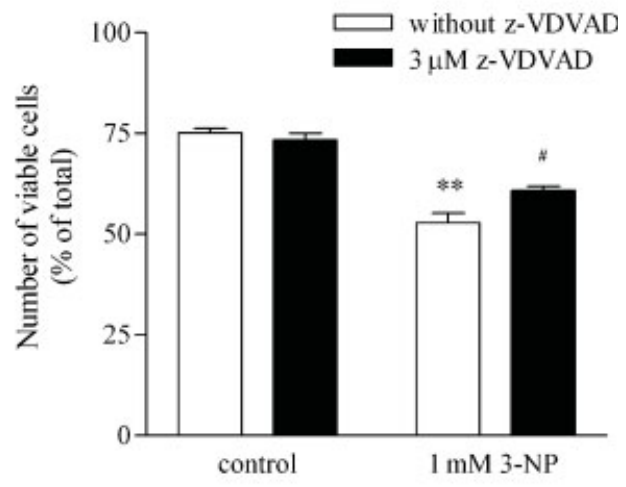

B: Quantification of viable cells (without fragmented/condensed chromatin). Cell viability was expressed as a percentage of the total number of cells (approximately 100 cells per field were counted). Results were expressed as the mean \pm SEM of four distinct experiments, performed in duplicates or triplicates. Statistical analysis: ${ }^{* *} P<0.01$, compared to untreated neurons; ${ }^{\#} P<0.05$, compared to 3-NP-treated neurons. [Color figure can be viewed in the online issue, which is available at www. interscience.wiley.com.]

rapid necrotic cell death was blocked by the NMDA receptor antagonist MK801, apoptosis was not attenuated by this compound but instead prevented by a protein synthesis inhibitor, cycloheximide. These data indicated that 3-NP-induced apoptosis required de novo gene expression. Alterations in gene expression are triggered by specific intracellular pathways that control the phosphorylation state of nuclear transcription factors. In accordance, Garcia et al. [2002] showed nuclear translocation of activated JNK, as well as hyperphosphorylation of the transcription factor c-Jun in striatal neurons upon 3-NP treatment. One possible target gene of the $\mathrm{JNK} / \mathrm{c}$-Jun module is the Fas ligand (FasL), as previously proposed based on different model systems of neuronal apoptosis [Le-Niculescu et al., 1999; MartinVillalba et al., 1999; Morishima et al., 2001]. The binding of FasL to its cognate receptor can lead to the activation of caspase- 8 . We previously showed that $3-\mathrm{NP}(1 \mathrm{mM})$ induced a twofold activation of caspase-8 [Almeida et al., 2004], raising the hypothesis of an involvement of JNK/c-Jun and the activation of FasL receptor. 

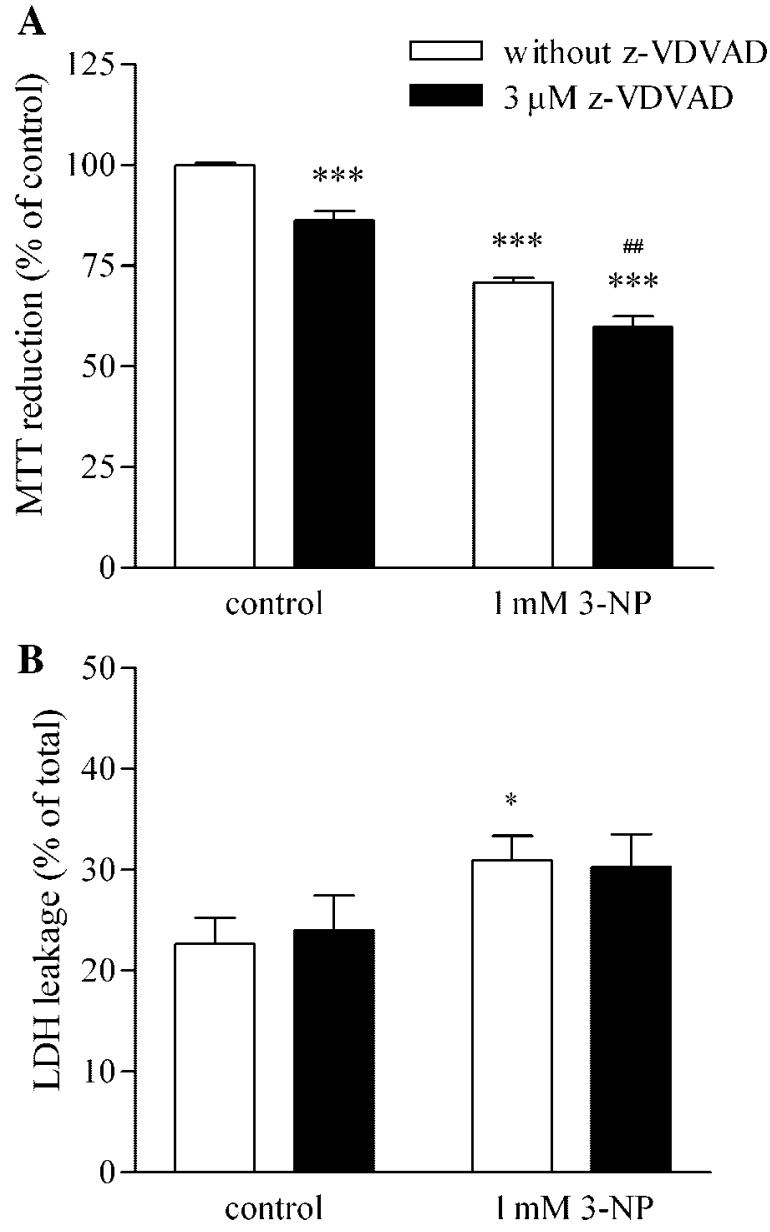

Fig. 4. Effect of z-VDVAD-fmk on cell reducing capacity and membrane integrity upon exposure to 3-NP. The cells were pretreated with $3 \mu \mathrm{M}$ z-VDVAD-fmk and further exposed to 1 $\mathrm{mM} 3-\mathrm{NP}$, for $24 \mathrm{~h}$. A: The reduction capacity of cells was analysed by measuring the reduction of tetrazolium salt (MTT) to formazan. These results were expressed as the percentage of optical density observed in the control (untreated cells). B: The integrity of the plasma membrane was determined by monitoring the leakage of $\mathrm{LDH}$, following the rate of conversion of $\mathrm{NADH}$ to $\mathrm{NAD}^{+}$, at $340 \mathrm{~nm}$. $\mathrm{LDH}$ released into the extracellular medium was expressed as a percentage of total LDH activity in the cells. Results were expressed as the mean \pm SEM of four distinct experiments, performed in duplicates or triplicates. Statistical analysis: $* P<0.05,{ }^{* * *} P<0.001$, compared to untreated neurons; ${ }^{\# \#} P<0.01$, compared to $3-N P$-treated neurons.

Under the present experimental conditions 3 -NP-induced caspase- 2 activation may have contributed for the release of cytochrome c. Previously, Enoksson et al. [2004] showed that despite permeabilising the outer mitochondrial membrane and causing cytochrome c release from this organelle, caspase-2 also disrupted the interaction of cytochrome $\mathrm{c}$ with anionic phospholipids, namely cardiolipin, and enhanced the release of this hemoprotein caused by an apoptotic stimulus. Nevertheless, complete blockade of caspase- 2 activity by zVDVAD-fmk $(3 \mu \mathrm{M})$ did not prevent 3-NPinduced cytochrome $\mathrm{c}$ release. Taking into account that caspase- 8 is activated by $3-\mathrm{NP}$ [Almeida et al., 2004], truncated Bid may trigger the release of cytochrome c. On the other hand, 3-NP-induced decrease of mitochondrial membrane potential may directly account for the release of this hemoprotein through the opening of the permeability transition pore [Green and Reed, 1998].

In addition, we showed that, in contrast to cytochrome c, z-VDVAD-fmk did not affect the release of AIF per se. In recent studies, Uren et al. [2005], reported that cytochrome c was easily released from permeabilised mitochondria than AIF, which required a more severe treatment. Thus, while cytochrome $\mathrm{c}$ is normally soluble in the intermembrane space, AIF seems to be partly attached to the mitochondrial inner membrane [Uren et al., 2005]. z-VDVADfmk alone also decreased the ability to reduce MTT, which depends on the overall cellular reducing capacity, without affecting the mitochondrial membrane potential or the integrity of the plasma membrane. These observations suggest that the inhibitor per se interferes with mitochondrial permeabilization without affecting mitochondrial function.

In the presence of $1 \mathrm{mM}$ 3-NP both caspasedependent and -independent cell death occur, as indicated by caspase- 2 and -3 activation and release of AIF from mitochondria. Although caspase-3-like activity was completely blocked by $\mathrm{z}$-VDVAD-fmk, this inhibitor only partly prevented chromatin fragmentation/condensation induced by $3-\mathrm{NP}$, suggesting that AIF may have contributed to the nuclear morphology observed. Wang et al. [2003] reported the involvement of these two pathways in cell death occurring in ST14A striatal cells stably expressing a mutant huntingtin truncation and in 10.5 weeks-old R6/2 mice, two HD models. AIF appears also to play an important role in several experimental models of neurodegeneration, including the death of photoreceptors induced by retinal detachment [Hisatomi et al., 2002], the in vivo neuronal death induced by brain trauma [Zhang et al., 2002] and cerebral ischemia [Zhu et al., 2003], hydrogen peroxide, peroxynitrite [Zhang et al., 2002], and the excitotoxin $\mathrm{N}$-methyl-D-aspartate [Yu et al., 2002]. 
In conclusion, our data demonstrate that cell death induced by 3 -NP, used to model mitochondrial dysfunction in HD, involves both caspase activation and mitochondrial release of AIF. z-VDVAD-fmk completely blocked the caspase-dependent pathway. However, it only partly protected from 3-NP-mediated cell death involving chromatin fragmentation/condensation. Thus, therapeutic strategies aimed at blocking both caspase-dependent and -independent pathways may protect against mitochondrial deregulation associated with neuronal loss in HD.

\section{REFERENCES}

Almeida S, Domingues A, Rodrigues L, Oliveira CR, Rego AC. 2004. FK506 prevents mitochondrial-dependent apoptotic cell death induced by 3-nitropropionic acid in rat primary cortical cultures. Neurobiol Dis 17:435-444.

Bae B, Xu H, Igarashi S, Fujimuro M, Agrawal N, Taya Y, Hayward SD, Moran TH, Montell C, Ross CA, Snyder SH, Sawa A. 2005. p53 mediates cellular dysfunction and behavioral abnormalities in Huntington's disease. Neuron 47:29-41.

Bergmeyer HU, Bernt E. 1974. UV-assay with pyruvate and NADH. Methods of enzymatic analysis. New York: Academic Press. pp 574-579.

Brito O, Almeida S, Oliveira CR, Rego AC. 2003. Bcl-2 prevents loss of cell viability and caspases activation induced by 3-nitropropionic acid in GT1-7 cells. Ann NY Acad Sci 1010:148-152.

Chen M, Ona VO, Li M, Ferrante RJ, Fink KB, Zhu S, Bian J, Guo L, Farrell LA, Hersch SM, Hobbs W, Vonsattel J-P, Cha J-H, Friedlander RM. 2000. Minocycline inhibits caspase-1 and caspase-3 expression and delays mortality in a transgenic mouse model of Huntington disease. Nat Med 6:797-801.

Chipuk JE, Green DG. 2005. Do inducers of apoptosis trigger caspase-independent cell death? Nat Rev Mol Cell Biol 6:797-801.

Enoksson M, Robertson JD, Gogvadze V, Bu P, Kropotov A, Zhivotovsky B, Orrenius S. 2004. Caspase-2 permeabilizes the outer mitochondrial membrane and disrupts the binding of cytochrome $\mathrm{c}$ to anionic phospholipids. J Biol Chem 279:49575-49578.

Garcia M, Vanhoutte P, Pages C, Besson MJ, Brouillet E, Caboche J. 2002. The mitochondrial toxin 3-nitropropionic acid induces striatal neurodegeneration via a c-Jun $\mathrm{N}$-terminal kinase/c-Jun module. J Neurosci 22:21742184.

Green DR, Reed JC. 1998. Mitochondria and apoptosis. Science 281:1309-1312.

Guo Y, Srinivasula SM, Druilhe A, Fernandes-Alnemri T, Alnemri ES. 2002. Caspase-2 induces apoptosis by releasing proapoptotic proteins from mitochondria. J Biol Chem 277:13430-13437.

Hermel E, Gafni J, Propp SS, Leavitt BR, Wellington CL, Young JE, Hackam AS, Logvinova AV, Peel AL, Chen SF, Hook V, Singaraja R, Krajewsk S, Goldsmith PC, Ellerby HM, Hayden MR, Bredesen DE, Ellerby LM. 2004.
Specific caspase interactions and amplification are involved in selective neuronal vulnerability in Huntington's disease. Cell Death Differ 11:424-438.

Hisatomi T, Sakamoto T, Goto Y, Yamanaka I, Oshima Y, Hata Y, Ishibashi T, Inomata H, Susin SA, Kroemer G. 2002. Critical role of photoreceptor apoptosis in functional damage after retinal detachment. Curr Eye Res 24: $161-172$

Kiechle T, Dedeoglu A, Kubilus J, Kowall NW, Beal MF, Friedlander R, Hersch SM, Ferrante RJ. 2002. Cytochrome c and caspase-9 expression in Huntington's disease. Neuromol Med 1:183-195.

Lassus P, Opitz-Araya X, Lazebnik Y. 2002. Requirement for caspase-2 in stress-induced apoptosis before mitochondrial permeabilization. Science 297:1352-1354.

Le-Niculescu H, Bonfoco E, Kasuya Y, Claret FX, Green DR, Karin M. 1999. Withdrawal of survival factors results in activation of the JNK pathway in neuronal cells leading to Fas ligand induction and cell death. Mol Cell Biol 19:751-763.

Li LY, Luo X, Wang X. 2001. Endonuclease G is an apoptotic DNase when released from mitochondria Nature 412:95-99.

Maianski NA, Roos D, Kuijpers TW. 2003. Tumor necrosis factor $\alpha$ induces a caspase-independent death pathway in human neutrophils. Blood 101:1987-1995.

Martin-Villalba A, Herr I, Jeremias I, Hahne M, Brandt R, Vogel J, Schenkel J, Herdegen T, Debatin KM. 1999. CD95 ligand (Fas-L/APO-1L) and tumor necrosis factorrelated apoptosis-inducing ligand mediate ischemiainduced apoptosis in neurons. J Neurosci 19:38093817.

Morishima Y, Gotoh Y, Zieg J, Barrett T, Takano H, Flavell R, Davis RJ, Shirasaki Y, Greenberg ME. 2001. Betaamyloid induces neuronal apoptosis via a mechanism that involves the c-Jun N-terminal kinase pathway and the induction of Fas ligand. J Neurosci 21:7551-7560.

Mosmann T. 1983. Rapid colorimetric assay for cellular growth and survival: Application to proliferation and cytotoxicity assays. J Immunol Methods 65:55-63.

Ona VO, Li M, Vonsattel J-P, Andrews LJ, Khan SQ, Chung WM, Frey AS, Menon AS, Li X-J, Stieg PE, Yuan J, Penney JB, Young AB, Cha J-H, Friedlander RM. 1999. Inhibition of caspase-1 slows disease progression in a mouse model of Huntington's disease. Nature 399:263267.

Pang Z, Geddes JW. 1997. Mechanisms of cell death induced by the mitochondrial toxin 3-nitropropionic acid: Acute excitotoxic necrosis and delayed apoptosis. J Neurosci 17:3064-3073

Paroni G, Henderson C, Schneider C, Brancolini C. 2002. Caspase-2 can trigger cytochrome c release and apoptosis from the nucleus. J Biol Chem 277:15147-15161.

Portera-Cailliau C, Hedreen JC, Price DL, Koliatsos VE. 1995. Evidence for apoptotic cell death in Huntington disease and excitotoxic animal models. J Neurosci 15: 3775-3787.

Read SH, Baliga BC, Ekert PG, Vaux DL, Kumar S. 2002. A novel apaf-1-independent putative caspase-2 activation complex. J Cell Biol 159:739-745.

Robertson JD, Enoksson M, Suomela M, Zhivotovsky B, Orrenius S. 2002. Caspase-2 acts upstream of mitochondria to promote cytochrome c release during etoposideinduced apoptosis. J Biol Chem 277:29803-29809. 
Sanchez I, Xu CJ, Juo P, Kakizaka A, Blenis J, Yuan J. 1999. Caspase- 8 is required for cell death induced by expanded polyglutamine repeats. Neuron 22:623-633.

Sedmak JJ, Grossero SE. 1977. A rapid, sensitive and versatile assay for protein using coomassie brilliant blue G250. Ann Biochem 79:544-552.

Susin SA, Lorenzo HK, Zamzami N, Marzo I, Snow BE, Brothers GM, Mangion J, Jacotot E, Costantini P, Loeffler M, Larochette N, Goodlett DR, Aebersold R, Siderovski DP, Penninger JM, Kroemer G. 1999. Molecular characterization of mitochondrial apoptosis-inducing factor. Nature 397:441-446.

Talanian RV, Quinlan C, Trautz S, Hackett MC, Mankovich JA, Banach D, Ghayur T, Brady KD, Wong WW. 1997. Substrate specificities of caspase family proteases. J Biol Chem 272:9677-9682.

Uren RT, Dewson G, Bonzon C, Lithgow T, Newmeyer DD, Kluck RM. 2005. Mitochondrial release of pro-apoptotic proteins. J Biol Chem 280:2266-2274.

Wang X, Zhu S, Drozda M, Zhang W, Stavrovskaya IG, Cattaneo E, Ferrante RJ, Kristal BS, Friedlander RM.
2003. Minocycline inhibits caspase-independent and -dependent mitochondrial cell death pathways in models of Huntington's disease. Proc Natl Acad Sci 100:1048310487.

Yu SW, Wang H, Poitras MF, Coombs C, Bowers WJ, Federoff HJ, Poirier GG, Dawson TM, Dawson VL. 2002 Mediation of poly(ADP-ribose) polymerase-1-dependent cell death by apoptosis-inducing factor. Science 297:259263.

Zhang X, Chen J, Graham SH, Du L, Kochanek PM, Draviam R, Guo F, Nathaniel PD, Szabo C, Watkins SC, Clark RS. 2002. Intranuclear localization of apoptosisinducing factor (AIF) and large scale DNA fragmentation after traumatic brain injury in rats and in neuronal cultures exposed to peroxynitrite. J Neurochem 82:181191.

Zhu C, Qiu L, Wang X, Hallin U, Cande C, Kroemer G, Hagberg H, Blomgren K. 2003. Involvement of apoptosis-inducing factor in neuronal death after hypoxia-ischemia in the neonatal rat brain. J Neurochem 86:306-317. 